\title{
Array-based comparative genomic hybridization for investigating chromosomal abnormalities in patients with learning disability: Systematic review meta-analysis of diagnostic and false-positive yields
}

Subu Subramonia-Iyer, $M B, M F P H^{1}$, Simon Sanderson, $M R C P, F F P H^{1,2}$, Gurdeep Sagoo, $M S c, P h D^{1}$, Julian Higgins, MA, PhD ${ }^{1,3}$, Hilary Burton, MA, FFPH ${ }^{1}$, Ron Zimmern, FRCP, FFPHM ${ }^{1}$, Mark Kroese, MRCGP, FFPH ${ }^{1}$, Pippa Brice, MA, $P h D^{1}$, and Charles Shaw-Smith, MA, $P h D^{4}$

\begin{abstract}
Purpose: Array-based comparative genomic hybridization is increasingly being used in patients with learning disability, in addition to existing cytogenetic techniques. This paper reports the results of an evaluation of this emerging technology and discusses the challenges faced in conducting the evaluation. Methods: Systematic review and meta-analysis of studies investigating patients with learning disability and dysmorphic features in whom conventional cytogenetic analysis has proven negative. Conventional indices of clinical validity could not be calculated, and we use an alternative, based on the extent to which array-based comparative genomic hybridization met its clinical objectives. Results: Seven studies (462 patients) were included. The overall diagnostic yield of causal abnormalities was 13\% (95\% confidence interval: $10-17 \%$; heterogeneity test statistic $\mathrm{I}^{2}=0 \%$ ), and the overall number needed to test was eight (95\% confidence interval: $6-10)$. The false-positive yield of noncausal abnormalities ranged from $5 \%$ to $67 \%$, although this range was only $5 \%$ to $10 \%$ in six of the studies. Conclusion: Although promising, there is insufficient evidence to recommend introduction of this test into routine clinical practice. A number of important technical questions need answering, such as optimal array resolution, which clones to include, and the most appropriate platforms. A thorough assessment of clinical utility and costeffectiveness compared with existing tests is also required. Genet Med 2007:9(2):74-79.
\end{abstract}

Key Words: Learning disability, mental retardation, array-based comparative genomic hybridization, microarrays, genetic testing

Considerable effort has been invested in establishing frameworks for the evaluation of genetic tests. A notable example is the ACCE format, which concentrates on four key areas: the analytical validity, clinical validity, clinical utility, and ethical, legal, and social implications of genetic tests. ${ }^{1}$ This paper reports the results of an evaluation of the clinical validity of array-based comparative genomic hybridization (array CGH) in patients with learning disability (LD) and discusses some of the challenges faced in evaluating an emerging genetic test. This project was undertaken at the request of the UK Genetic Test-

From the ${ }^{I}$ Public Health Genetics Unit, Cambridge; ${ }^{2}$ General Practice and Primary Care Research Unit, University of Cambridge, Cambridge; ${ }^{3} \mathrm{MRC}$ Biostatistics Unit, Cambridge; ${ }^{4}$ Department of Medical Genetics, Cambridge University Hospitals NHS Trust, Cambridge, United Kingdom.

Simon Sanderson, MRCP, FFPH, Strangeways Research Laboratories, Worts Causeway, Cambridge CB1 8RN, UK; E-mail: simon.sanderson@srl.cam.ac.uk

The authors declare no conflict of interest.

Submitted for publication June 12, 2006.

Accepted for publication December 8, 2006.

DOI: 10.1097/GIM.0b013e31803141f2 ing Network to examine any implications for its use in the UK National Health Service.

LD can be defined as a significant impairment of cognitive and adaptive functions, with onset before 18 years of age..$^{2,3}$ The disease burden from LD is substantial: the World Health Organization has estimated a prevalence of $3 \%$ in industrialized countries. ${ }^{4}$ Genetic factors have been estimated to be the main cause of LD in approximately half of all patients with severe $\mathrm{LD}$ and approximately $15 \%$ of patients presenting with mild LD. ${ }^{5}$ Chromosomal abnormalities are present in approximately $16 \%$ of individuals with LD (range: $4.0-34.1 \%){ }^{6}$ These structural chromosomal abnormalities are often associated with dysmorphic features, congenital abnormalities, and growth problems, many of which are nonspecific. Some syndromes, such as Down syndrome and Turner syndrome, are due to copy number changes involving whole chromosomes and are easily detectable with the light microscope. Other syndromes, such as cri-du-chat syndrome (deletion 5p), are due to loss or gain of part of a chromosome and are detectable by alterations in the pattern of G-banding and are again visible by light microscopy. Techniques such as fluorescent in situ hybridization (FISH) and multiplex ligation-dependent probe 
amplification (MLPA) can identify submicroscopic chromosome deletions and even deletions of single genes located on specific chromosomes. ${ }^{7}$ Deletions causing Williams syndrome, Prader-Willi syndrome, and the 22q11 deletion syndrome, as well as subtelomeric copy number changes, fall into this category. A new method of analysis, array CGH, is now being used to investigate children with $\mathrm{LD}$ and dysmorphic features when conventional cytogenetic analysis results proved negative. ${ }^{89}$

The clinical assessment of children with LD typically includes clinical examination by a pediatrician, followed by appropriate investigations, which consist of biochemical and hematological tests as well as chromosomal tests. At present, a karyotype analysis is performed, followed by FISH or MLPA where indicated. Currently, array CGH is used almost entirely in a research setting as an add-on test to look for chromosomal abnormalities that are strongly suspected on clinical grounds and when results of existing cytogenetic tests have proved negative.

\section{ARRAY-BASED COMPARATIVE GENOMIC HYBRIDIZATION}

CGH is a method for identifying copy-number variations (amplifications or deletions) within the genome. ${ }^{8}$ The procedure relies on combining fluorescence with microarray technology to allow not only the identification and measurement of changes in DNA sequence copy number, but also the simultaneous mapping of these sites within the genomic sequence. Because a microarray can contain thousands of individual DNA probes (or reporter sequences) representing the complete genome (with partial or complete sequence information), hybridization at a specific spot provides a much more precise indication of the site of aberrations in the genomic sequence than a band on a chromosome could do, yet still within a single experiment. Array CGH has many potential advantages over other cytogenetic techniques because it can provide rapid genome-wide assessments at a high resolution $(\leq 1 \mathrm{Mb})$, and the information provided can be linked directly to physical and genetic maps of the human genome. Array CGH can detect single-copy gains and losses in specific chromosomal areas, telomeres, and whole chromosomes and thus has the potential to completely replace currently available cytogenetic techniques for the detection of known genetic abnormalities and clinical syndromes.

The main drawback to using array CGH in LD is its potential for identifying novel copy number variations that may not be responsible for the patient's LD. ${ }^{10,11}$ Even if a variant is present in an affected individual but absent from "normal" parental genomes, it does not necessarily follow that it is a pathogenic change, and it may rather represent an innocuous copy-number polymorphism (a normal variation in the human genome). Probes for array CGH generally avoid the use of sequences that hybridize to multiple genomic locations and thus are shielded from the detection of large-scale copy-number variations to some extent. The construction and interpretation of CGH arrays are a skilled process, requiring communication between specialists to associate apparent abnormalities with specific clinical features. To facilitate this information sharing, a number of international databases have been established, such as DECIPHER (Database of Chromosomal Imbalance and Phenotype in Humans Using Ensemble Resources; http://www.sanger.ac.uk/PostGenomics/decipher/), the Toronto-based Database of Genomic Variants (http://projects. tcag.ca/variation/), and ECARUCA, the European Cytogeneticists Association Register of Unbalanced Chromosome Aberrations (http://www.ecaruca.net/).

Clinicians determine the clinical relevance of identified genetic abnormalities to patients' phenotypes by using databases such as DECIPHER, by the putative functional location of detected abnormalities, and whether the abnormality has been inherited from the parents (who may or may not be phenotypically normal).

\section{MATERIALS AND METHODS}

\section{Test definition}

The concept of an assay can be distinguished from that of a test. An assay is any method for analyzing or determining the presence of a substance in a sample, and a test is the application of an assay in a clinical context for a specific purpose; thus, the same assay may be used in a number of different tests. Following on from this distinction, a genetic test is the use of an assay to detect specific genetic variants, in relation to a particular target disorder, in a defined population, for a specific purpose. ${ }^{12}$ This distinction is important because analytical validity is primarily concerned with evaluating the performance of the assay in the laboratory (accuracy and reliability), whereas clinical validity and clinical utility are concerned with evaluating the performance of the test in patients. For the purposes of this evaluation, we defined the assay as array $\mathrm{CGH}$ and the test as:

- The application of array CGH (the assay)

- For LD (the target disorder)

- In patients with dysmorphic features and negative results from conventional cytogenetic analysis (the population)

- To identify genetic subsets of the LD phenotype (the purpose)

Fundamentally, in the context of this evaluation, array CGH is not being used in the conventional sense to diagnose $\mathrm{LD}$ because this diagnosis has already been established; it is being used to classify the putative cause of the patient's LD.

\section{Systematic review inclusion criteria}

Studies were included that used array CGH to identify genetic abnormalities in patients with LD and developmental delay or dysmorphism, in whom results of conventional cytogenetic analysis proved negative. Both case series and cohort studies were eligible for inclusion.

\section{Search strategy and data extraction}

PubMed, MEDLINE, EMBASE, and BIOSIS databases were searched during February 2006 using both free text and MeSH terms, appropriately modified for the specific database (Ap- 
pendix). No language or other search restrictions were imposed. Reference lists of primary studies were scrutinized for additional references, and experts in the field were contacted in an attempt to identify other unpublished studies. Two reviewers (S.S.-I. and G.S.) independently extracted data using prepiloted proformas. Reviewers compared results and resolved any differences through discussion or by involving other members of the team (S.S. and C.S.-S.).

\section{Assessment of study quality}

No quantitative methods were used to rate study quality, but the following quality indicators were assessed ${ }^{1,13}$ : (1) clear description of the setting and study population; (2) whether criteria used for patient selection were clearly described; (3) evidence of appropriate pretesting with karyotyping, FISH, and telomere tests; (4) whether control samples were included and, if so, described clearly; (5) description of the array CGH platform, software, and assay process; (6) description of steps to identify and exclude known copy-number polymorphisms using genome databases; (7) appropriate follow-up testing; (8) clear description of the process of interpretation of array CGH results.

\section{Statistical analysis}

Array CGH can identify hitherto unknown genetic abnormalities previously undetectable by other cytogenetic techniques, taking us into an arena where there is no gold-standard reference test available that can be applied to all patients. Conventional measures of test discrimination, such as the sensitivity and specificity, cannot be used to evaluate its performance. We therefore adopted a pragmatic alternative, which was to evaluate the extent to which array CGH met its clinical objective, ${ }^{14,15}$ which is to identify genotypic subsets of the $\mathrm{LD}$ and dysmorphism phenotype. We measured the effectiveness by quantifying

- The diagnostic yield: proportion of causal variants detected in those tested

- The false-positive yield: proportion of noncausal variants detected in those tested

The number needed to test was also determined as the number of tests performed to identify one causal variant (calculated as 1 /diagnostic yield).

Before meta-analysis, consistency of findings (often called heterogeneity) was tested using standard $\chi^{2}$ methods and by using the $\mathrm{I}^{2}$ statistic, which describes the proportion of total variation in estimates due to heterogeneity rather than random error. ${ }^{16,17}$ The meta-analysis was conducted using a randomeffects model, which assumes that heterogeneity can be represented by a distribution of underlying effects and is conventionally a normal distribution.

\section{RESULTS}

\section{Study characteristics}

Seven primary studies, incorporating a total of 462 subjects, were identified that met the inclusion criteria (Table 1).,718-22
Only one study was conducted in Asian patients. ${ }^{19}$ All the studies were relatively small, ranging from 20 to 140 patients. All studies included sampling of control DNA as part of their protocol. The five studies investigating $1-\mathrm{Mb}$ resolution arrays all used the same array as the Shaw-Smith et al. study, ${ }^{7}$ one used an array with a resolution of $50 \mathrm{~kb},{ }^{20}$ and another used a specific set of 2173 clones, resulting in an average resolution of 1.4 Mb. ${ }^{19}$ Control samples varied from 2 to 40 normal people, whereas Menten and colleagues ${ }^{18}$ used samples from other patients in the cohort as controls. There was some variation in the clinical criteria for patient selection and testing, with some investigators using a clinical severity score. ${ }^{7,20,21}$

\section{Test performance}

The combined diagnostic yield of causal genetic abnormalities in the seven studies was $13 \%$ (95\% confidence interval [CI]: $10-17 \%$; Table 2 and Fig. 1). There was no evidence of heterogeneity $\left(\chi^{2}=2.41, P=0.878 ; \mathrm{I}^{2}=0 \%\right)$. The number needed to test was eight (95\% CI: 6-10). The proportion of noncausal variants detected by array CGH ranged from $5 \%$ to $67 \%$. However, the range is distorted by a high false-positive rate in the study by Miyake et al. ${ }^{19}$; the other studies ranged 5\% to $10 \%$. A meta-analysis of the five studies, excluding Miyake et al., ${ }^{19}$ gives a combined false-positive yield of $7 \%$ (range: 5-10\%).

\section{DISCUSSION}

This meta-analysis of seven studies has found that array CGH is able to identify causal genetic abnormalities in patients with LD and dysmorphism, in whom conventional cytogenetic analysis results had proved negative. The variability in diagnostic yield is solely due to random error and cannot be attributed to underlying study heterogeneity $\left(\mathrm{I}^{2}=0 \%\right)$. We believe that we have identified all currently available studies by using a comprehensive and sensitive search strategy. However, because of the low number of included studies, conventional graphical methods for assessing publication bias (such as funnel plots) were not used. ${ }^{23}$

Array CGH also identifies genetic abnormalities that are deemed to be noncausal; if the study by Miyake et al. ${ }^{19}$ is excluded (false-positive yield: 67\%), the false-positive yield is an acceptable $5 \%$ to $10 \%$. However, the reasons for the extreme results of Miyake et al. ${ }^{19}$ are unclear; it does not appear to be related to the array's resolution because they used the lowest resolution array $(1.4 \mathrm{Mb})$ and the study with the highest resolution array (de Vries et al..$^{20}$ ) had one of the lowest false-positive yields (5\%). The spectrum of patients tested also appears to be similar to that of other studies.

One possible explanation is that there are important differences in the design, calibration, and use of their array and especially their choice of clones, although the similarity of the diagnostic yield compared with the other studies is striking. Another explanation is that ethnicity may be influencing the results, as this was the only study reporting data from patients in the Eastern hemisphere. It will be interesting to see whether 
Table 1

Identified studies and their characteristics

\begin{tabular}{|c|c|c|c|c|c|c|}
\hline Author/year & Country & Patients & $\begin{array}{l}\text { No. of } \\
\text { patients }\end{array}$ & Setting & Controls & $\begin{array}{l}\text { Array } \\
\text { methods/resolution }\end{array}$ \\
\hline Menten et al., $2005^{18}$ & Belgium & $\begin{array}{l}\text { Idiopathic MR with multiple congenital } \\
\text { anomalies }\end{array}$ & 140 & Genetics service & $\begin{array}{l}\text { Other patients in the } \\
\text { cohort }\end{array}$ & $1-\mathrm{Mb}$ array $^{7}$ \\
\hline Miyake et al., $2006^{19}$ & Japan & $\begin{array}{l}\text { Idiopathic MR with some dysmorphic } \\
\text { features }\end{array}$ & 30 & Various & $\begin{array}{l}2(1 \mathrm{M}, 1 \mathrm{~F}) \text { negative, } \\
1 \text { positive control }\end{array}$ & $\begin{array}{l}\text { For whole genome: } 2173 \\
\text { FISH-confirmed } \\
\text { clones }\end{array}$ \\
\hline de Vries et al., $2005^{20}$ & Netherlands & $\begin{array}{l}\text { MR, negative for karyotyping and MLPA. } \\
\text { Scored by a checklist of clinical criteria } \\
(0-10)\end{array}$ & 100 & Genetics service & $\begin{array}{l}72 \text { parents of the } \\
\text { cases }\end{array}$ & $\begin{array}{l}\text { Tiling resolution whole } \\
\text { genome array }\end{array}$ \\
\hline $\begin{array}{l}\text { Shaw-Smith et al., } \\
\qquad 2004^{7}\end{array}$ & UK, France & $\begin{array}{l}\text { Moderate to severe MR, } \\
\text { nonconsanguineous, with at least } 1 \text { (of } \\
\text { 4) clinical criteria }\end{array}$ & 50 & Genetics service & $\begin{array}{l}\text { Pooled DNA from } \\
\text { normal people }(20 \\
\text { M, 20 F) }\end{array}$ & $1-\mathrm{Mb}$ array $^{7}$ \\
\hline $\begin{array}{l}\text { Schoumans et al., } \\
\qquad 2005^{21}\end{array}$ & Sweden & $\begin{array}{l}\text { Mild to severe MR, with phenotype } \\
\text { suggestive of chromosomal origin, i.e., } \\
\text { dysmorphism, malformations, and/or } \\
\text { family history, scoring at least } 3 \text { points } \\
\text { on the de Vries et al. checklist }\end{array}$ & 41 & $\begin{array}{l}\text { Molecular } \\
\text { medicine }\end{array}$ & $\begin{array}{l}\text { Reference DNA of a } \\
\text { pool of } 10 \text { normal } \\
\text { individuals }\end{array}$ & $1-\mathrm{Mb}$ array $^{7}$ \\
\hline $\begin{array}{l}\text { Rosenberg et al., } \\
2005^{22}\end{array}$ & $\begin{array}{l}\text { Netherlands, } \\
\text { Brazil, UK }\end{array}$ & $\begin{array}{l}\text { Mild to severe MR, with cranial/facial } \\
\text { dysmorphisms and at least one } \\
\text { additional congenital abnormality. } \\
\text { Family history and consanguinity were } \\
\text { not considered }\end{array}$ & 81 & Genetics service & $\begin{array}{l}100 \text { control } \\
\text { observations for } \\
\text { each chromosome } \\
\text { pair }\end{array}$ & $1-\mathrm{Mb}$ array $^{7}$ \\
\hline Vissers, $2003^{26}$ & Netherlands, US & $\begin{array}{l}\text { Patients with MR and additional } \\
\text { dysmorphisms, scoring } \geq 3 \text { points on } \\
\text { de Vries' checklist }\end{array}$ & 20 & Genetics service & $\begin{array}{l}\text { Four normal healthy } \\
\text { blood donors }(2 \\
\text { M, } 2 \text { F) }\end{array}$ & 1-Mb array ${ }^{7}$ \\
\hline
\end{tabular}

MR, mental retardation; FISH, fluorescent in situ hybridization; MLPA, multiplex ligation-dependent probe amplification; M, male; F, female.

Table 2

Genetic abnormalities identified by array comparative genomic hybridization in idiopathic learning disability

\begin{tabular}{|c|c|c|c|c|c|c|}
\hline Author/year & Resolution & $\begin{array}{l}\text { No. of } \\
\text { patients }\end{array}$ & $\begin{array}{c}\text { Patients with } \\
\text { noncausal abnormality }\end{array}$ & $\begin{array}{l}\text { False-positive } \\
\text { yield, } \%\end{array}$ & $\begin{array}{l}\text { Patients } \\
\text { with causal abnormality }\end{array}$ & $\begin{array}{l}\text { Diagnostic } \\
\text { yield, } \%\end{array}$ \\
\hline Menten et al., $2005^{18}$ & $1 \mathrm{Mb}$ & 140 & 9 & 6.4 & 19 & 13.6 \\
\hline Miyake et al., $2006^{19}$ & $1.4 \mathrm{Mb}$ & 30 & 20 & 66.7 & 5 & 16.7 \\
\hline de Vries et al., $2005^{20}$ & $50 \mathrm{~kb}$ & 100 & 5 & 5.0 & 10 & 10.0 \\
\hline Shaw-Smith et al., $2004^{7}$ & $1 \mathrm{Mb}$ & 50 & 5 & 10.0 & 7 & 14.0 \\
\hline Schoumans et al., $2005^{21}$ & $1 \mathrm{Mb}$ & 41 & $\mathrm{NS}^{a}$ & $\mathrm{NS}^{a}$ & 4 & 9.8 \\
\hline Rosenberg et al., $2005^{22}$ & $1 \mathrm{Mb}$ & 81 & 7 & 8.6 & 13 & 16.0 \\
\hline Vissers, $2003^{26}$ & $1 \mathrm{Mb}$ & 20 & 1 & 5.0 & 2 & 10.0 \\
\hline
\end{tabular}

${ }^{a}$ Not stated (NS): A total of 151 copy number polymorphisms (CNPs) detected in the cohort; number of patients with CNPs not stated.

future studies conducted in Asian patients report similar results.

The evaluation of emerging genetic tests, such as array CGH, is challenging because it has the potential to outperform currently available technologies, raising a number of important issues that may be applicable to other test evaluations. The first is the need for a very clear definition of the test being evaluated, and the conceptual distinction between assay and test is helpful here. There is also the question of how genetic disorders should be defined for evaluation purposes because they may be defined by reference to the phenotype, the genotype, or to a combination of the two. When evaluating a test, it is important that the target disorder is defined either by reference to the phenotype or for a genotypic definition, by an alternative assay reference method to prevent the problem of incorporation bias. $^{12,24}$ Thus, in a known LD syndrome, such as DiGeorge syndrome, the traditional evaluative approach can be applied using either the phenotype or the genotype as the reference standard (assuming that the deletion could be detected by an alternative technology such as FISH). In this particular setting, the definition of the target disorder was very broad and largely encompassed patients with hitherto unknown genetic abnormalities. This meant that a phenotypic reference standard could not be defined. 


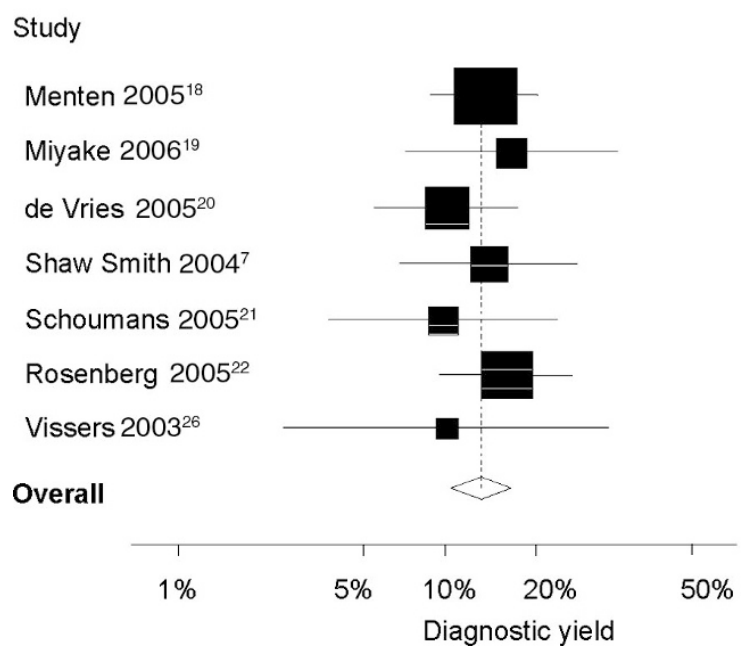

Diagnostic yield

$(95 \% \mathrm{Cl})$

$\begin{array}{lr}14 \%(9 \%, 20 \%) & 31.6 \\ 17 \%(7 \%, 34 \%) & 8.0 \\ 10 \%(5 \%, 18 \%) & 17.3 \\ 14 \%(7 \%, 27 \%) & 11.6 \\ 10 \%(4 \%, 23 \%) & 7.0 \\ 16 \%(10 \%, 26 \%) & 21.0 \\ 10 \%(3 \%, 32 \%) & 3.5 \\ 13 \%(10 \%, 17 \%) & 100.0\end{array}$

Fig. 1. Random effects meta-analysis of diagnostic yield from array-based comparative genomic hybridization in patients with learning disability. CI, confidence interval.

Test evaluation was further hampered by the lack of an available genotypic reference standard for array CGH that could independently verify the "truth" in all subjects, especially in those testing negative. Although it may not always be possible to calculate the clinical sensitivity and specificity, the evaluation of test effectiveness is a pragmatic alternative. Indices such as the diagnostic yield, false-positive yield, and number needed to test coupled with data from control populations can provide useful indicators of test performance that are clinically meaningful (Table 3).

\section{Implications for clinical practice}

The results of this systematic review suggest that array CGH is a promising technology for investigating patients with $\mathrm{LD}$ in whom conventional cytogenetic analysis has proven negative. Before widespread introduction of this technology into clinical practice, a number of important technical questions need answering, such as the optimal array resolution, the choice of included clones, the most appropriate platforms, and the establishment of quality assurance mechanisms for use in a clinical setting. Although there is a need for more studies evaluating the test in highly selected patient groups, it is also important in the interests of the most equitable and efficient use of resources that the performance of array CGH be com-

\section{Table 3}

Examining the prevalence of genetic abnormalities detected by array comparative genomic hybridization in LD patients with dysmorphic features compared with population controls

\begin{tabular}{lcc}
\hline & $\begin{array}{c}\mathrm{LD}+\text { dysmorphic } \\
\text { features }\end{array}$ & $\begin{array}{c}\text { Normal } \\
\text { population controls }\end{array}$ \\
\hline Causal genomic variant & $\mathrm{a}$ & $\mathrm{b}$ \\
Noncausal genomic variant & $\mathrm{c}^{a}$ & $\mathrm{~d}^{a}$ \\
Array negative & $\mathrm{e}$ & $\mathrm{f}$ \\
\hline
\end{tabular}

${ }^{a}$ If the test was working correctly, we would expect $\mathrm{c}$ and $\mathrm{d}$ to be equal. LD, learning disability. pared directly with existing cytogenetic tests as a first-line replacement test in the general LD patient population..$^{25}$ The prevalence of normal copy-number variants may be much higher in the general patient population and the signal-tonoise ratio may be very different. More information is also needed about the clinical utility of array CGH testing. Its potential benefits include the considerable value that parents and caregivers place on a diagnosis, providing valuable information for explaining the LD diagnosis, and for improving clinical management, reproductive choice, access to genetic counseling, and reducing the "diagnostic odyssey" of multiple investigations that patients with LD often endure. Potential harms may include false reassurance due to false-negative results or a sense of fatalism, which may be fostered by a genetic tests result indicating an abnormality. There are also important questions about cost-effectiveness, as array CGH is currently more expensive and time-consuming than existing technologies (although these costs are likely to decrease over time). Counseling patients and parents about the suitability of array CGH testing and results is likely to have a significant impact on clinical workload. Thus, we recommend that pragmatic clinical trials in a service setting to examine these issues. The challenge of patient and professional education, the need for careful interpretation of the results, and the impact of array CGH test on clinical services must be quantified before array CGH test can be recommended as a first-line test to replace karyotyping in the assessment of patients with LD.

\section{Implications for the evaluation of genetic tests}

The unique features of many emerging genetic tests create problems for those attempting to produce or use evaluation frameworks, and due consideration must be given to providing flexibility for individual evaluations. ${ }^{24}$ Second, for newly emerging technologies, identification of either a phenotypic or genotypic reference standard can be problematic. In these situations, conventional indices of test discrimination cannot be 
calculated, but it is worth exploring pragmatic indices based on clinical effectiveness. Third, the movement of technologies from a research to a clinical setting requires time to build experience of test use and an evidence base; we suggest that the routine and prospective collection of data in databases, such as DECIPHER, is a key factor for evaluating the performance of array $\mathrm{CGH}$, and similar models should be used for other emerging novel tests.

\section{APPENDIX: SEARCH STRATEGIES}

\section{Medline}

((learning disability) OR (mental retardation) OR (abnormalities) OR (learning disorders) OR (developmental disabilities) OR (syndromes) OR (multiple congenital anomalies)) AND (array-cgh OR microarray).

\section{Embase}

1 array-cgh OR microarray

2 DNA-MICROARRAY\#.DE. OR GENE-EXPRESSIONPROFILING\#.DE.

3 mental ADJ retardation OR learning ADJ disorders OR learning ADJ disability OR developmental ADJ disorders OR abnormalities

4 LEARNING-DISORDER.DE. OR EDUCATION.W..DE. OR MENTAL-DEFICIENCY.DE. OR FRAGILE-X-SYNDROME.

DE. OR AUTISM.W..DE.

\section{OR 2}

63 OR 4

75 AND 6

\section{Biosis}

al: (array-cgh OR microarray) and ts: "mental retardation" or "learning disability" or "learning disorder" or "developmental disorder" or "abnormalities" and su: (Human).

\section{ACKNOWLEDGMENTS}

This work was commissioned by the NHS UK Genetic Testing Network and supported by the Department of Health.

\section{References}

1. Haddow J, Palomaki G. ACCE: a model process for evaluating data on emerging genetic tests. In: Khoury M, Little J, Burke W, editors. Human genome epidemiology. New York: Oxford University Press, 2004:217-233.

2. Department of Health. Valuing people. A new strategy for learning disability for the 21st century. London: The Stationery Office, 2001.
3. World Health Organization. The ICD-10 classification of mental and behavioural disorders. Clinical descriptions and diagnostic guidelines. Geneva: World Health Organization, 1992.

4. Joint Commission on International Aspects of Mental Retardation. Mental retardation: meeting the challenge. WHO Offset Publication 86. Geneva: World Health Organization, 1989.

5. Hagberg B, Kyllerman M. Epidemiology of mental retardation-a Swedish survey. Brain Dev 1983;5:441-449.

6. Xu J, Chen Z. Advances in molecular cytogenetics for the evaluation of mental retardation. Am J Med Genet C Semin Med Genet 2003;117:15-24.

7. Shaw-Smith C, Redon R, Rickman L, Rio M, et al. Microarray based comparative genomic hybridisation (array-CGH) detects submicroscopic chromosomal deletions and duplications in patients with learning disability/mental retardation and dysmorphic features. J Med Genet 2004;41:241-248.

8. Cheung SW, Shaw CA, Yu W, Li J, et al. Development and validation of a CGH microarray for clinical cytogenetic diagnosis. Genet Med 2005;7:422-432.

9. Yu W, Ballif BC, Kashork CD, Heilstedt HA, et al. Development of a comparative genomic hybridization microarray and demonstration of its utility with 25 wellcharacterized 1p36 deletions. Hum Mol Genet 2003;12:2145-2152.

10. Iafrate AJ, Feuk L, Rivera MN, Listewnik ML, et al. Detection of large-scale variation in the human genome. Nat Genet 2004;36:949-951.

11. Sebat J, Lakshmi B, Troge J, Alexander J, et al. Large-scale copy number polymorphism in the human genome. Science 2004;305:525-528.

12. Kroese M, Zimmern RL, Sanderson SP. Genetic tests and their evaluation: can we answer the key questions? Genet Med 2004;6:475-480.

13. Little J, Bradley L, Bray MS, Clyne M, et al. Reporting, appraising, and integrating data on genotype prevalence and gene-disease associations. Am J Epidemiol 2002; 156:300-310.

14. Cochrane A. Effectiveness and efficiency; random reflections on health services. London: Nuffield Provincial Hospitals Trust, 1972.

15. Last J A dictionary of epidemiology. New York: Oxford University Press, 2001.

16. Higgins JP, Thompson SG. Quantifying heterogeneity in a meta-analysis. Stat Med 2002;21:1539-1558.

17. Higgins JP, Thompson SG, Deeks JJ, Altman DG. Measuring inconsistency in metaanalyses. BMJ 2003;327:557-560.

18. Menten B, Buysse K, Vandesompele J, De Smet E, et al. Identification of an unbalanced $\mathrm{X}$-autosome translocation by array CGH in a boy with a syndromic form of chondrodysplasia punctata brachytelephalangic type. Eur J Med Genet 2005;48:301-309.

19. Miyake N, Shimokawa O, Harada N, Sosonkina N, et al. No detectable genomic aberrations by BAC array CGH in Kabuki make-up syndrome patients. Am J Med Genet A 2006;140A:291-293.

20. de Vries BB, Pfundt R, Leisink M, Koolen DA, et al. Diagnostic genome profiling in mental retardation. Am J Hum Genet 2005;77:606-616.

21. Schoumans J, Ruivenkamp C, Holmberg E, Kyllerman M, Anderlid BM, Nordenskjold M. Detection of chromosomal imbalances in children with idiopathic mental retardation by array based comparative genomic hybridisation (arrayCGH). J Med Genet 2005;42:699-705.

22. Rosenberg C, Knijnenburg J, Bakker E, Vianna-Morgante A, et al. Array-CGH detection of micro rearrangements in mentally retarded individuals: clinical significance of imbalances present both in affected children and normal parents. J Med Genet 2006;43:180-186. [E-pub ahead of print June 24, 2005.]

23. Higgins JP, Spiegelhalter DJ. Being sceptical about meta-analyses: a Bayesian perspective on magnesium trials in myocardial infarction. Int J Epidemiol 2002;31:96-104.

24. Sanderson S, Zimmern R, Kroese M, Higgins J, Patch C, Emery J, et al. How can the evaluation of genetic tests be enhanced? Lessons learned from the ACCE framework and evaluating genetic tests in the United Kingdom. Genet Med 2005;7:495-500.

25. Bossuyt PM, Irwig L, Craig J, Glasziou P. Comparative accuracy: assessing new tests against existing diagnostic pathways. BMJ 2006;332:1089-1092.

26. Vissers LE, de Vries BB, Osoegawa K, Janssen IM, et al. Array-based comparative genomic hybridization for the genomewide detection of submicroscopic chromosomal abnormalities. Am J Hum Genet 2003;73:1261-1270. 